\title{
A First Evaluation of $\mathrm{OMNI}{ }^{\circledR}$, A New Device for Continuous Renal Replacement Therapy
}

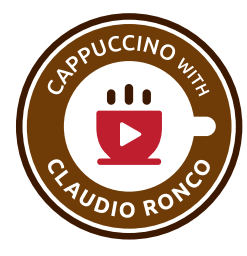

\author{
Pierre Schläpfer ${ }^{a, b}$ Jean-Daniel Durovray ${ }^{b}$ Valery Plouhinec $^{a}$ \\ Cristiano Chiappa $^{a}$ Rinaldo Bellomo ${ }^{c}$ Antoine Schneider ${ }^{a}$ \\ ${ }^{a}$ Adult Intensive Care Unit, and ${ }^{b}$ Anesthesiology Department, Centre Hospitalier Universitaire Vaudois (CHUV), \\ Lausanne, Switzerland; ' Intensive Care Unit, Austin Health, Heidelberg, Vic., Australia
}

\section{Key Words}

Acute kidney injury · Renal replacement therapy · Blood purification $\cdot$ Renal dose

\begin{abstract}
Background: Omni ${ }^{\circledR}$ (B. Braun, Germany) is a new-generation, continuous renal replacement therapy (CRRT) machine designed to improve user interface, minimize downtime and optimize renal dose delivery. It was never tested in humans. Methods: We used Omni ${ }^{\circledR}$ to provide CRRT in 10 critically ill patients. We collected therapy data, metabolic parameters and evaluated user's satisfaction with a survey. Results: CRRT was delivered using Omni ${ }^{\circledR}$ in CVVH-heparin (6 patients) and CVVHD-citrate (4 patients) modes for a total duration of $617.7 \mathrm{~h}$. No adverse event was observed. The mean filter life was 22.8 (CVVH-heparin) and 33.5 (CVVHD-citrate) h. Alarms-related downtime corresponded to $5.9 \%$ of total therapy time. Delivered renal dose was $96.6 \%$ of prescribed. Satisfactory metabolic control and fluid removal were achieved. Overall, users evaluated interface, design and usability as excellent. Conclusion: CRRT in CVVH-heparin and CVVHD-citrate modes was provided using Omni ${ }^{\circledR}$ in a safe and efficient way for 10 critically ill patients.

Video Journal Club 'Cappuccino with Claudio Ronco' at http://www.karger.com/?doi=451053. @ 2016 S. Karger AG, Basel
\end{abstract}

\section{Introduction}

Since the first description of continuous renal replacement therapy (CRRT) by Kramer et al. [1], several generations of devices have gradually improved the safety and feasibility of CRRT for critically ill patients with acute kidney injury. Among these improvements, the use of double lumen catheters (eliminating the need for an arterial access), the implementation of volumetric pumps into the RRT device, and the overall precision of weighing scales may be recognized as major steps. More recently, the implementation of citrate anticoagulation [24] protocols [5-7] built in to RRT devices has increased filter life and made therapy delivery safer and more reliable [8-10]. However, several challenges remain to optimize RRT in critical illness [11]. Among these, improving fluid balance precision [12], optimizing alarms management and minimizing therapy downtime have been identified as critical. In addition, the need to simplify therapy management, decrease nursing workload and improve user interface remains an important consideration $[13,14]$.

$\mathrm{Omni}^{\circledR}$ (B. Braun, Melsungen, Germany), a new-generation CRRT device, has recently been designed with the aim of improving therapy accuracy and fluid balance management. Such improvements are thought to facili-

\section{KARGER}

E-Mail karger@karger.com

www.karger.com/bpu
(C) 2016 S. Karger AG, Basel

0253-5068/16/0433-0011\$39.50/0
Dr. Antoine Schneider

Adult Intensive Care Unit

Centre Hospitalier Universitaire Vaudois (CHUV)

21, Avenue du Bugnon, $\mathrm{CH}-1011$ Lausanne (Switzerland)

E-Mail antoine.schneider@ chuv.ch 
tate the achievement of target renal dose delivery, net fluid removal and ease of use. However, Omni ${ }^{\circledR}$ has not yet been tested in real-life conditions.

We sought to determine the safety and feasibility of providing CRRT with Omni ${ }^{\circledR}$ in 10 critically ill patients. We also assessed user (nurses) satisfaction and aimed to provide direct feedback to the manufacturer regarding issues raised and provide user interface improvement suggestions.

\section{Methods}

\section{Study Design and Population}

This prospective observational study was performed in our 35bed medico-surgical ICU within a 1,500 beds teaching hospital in Lausanne, Switzerland. We included 10 patients with an indication for CRRT for an estimated duration of more than $72 \mathrm{~h}$ between February and November 2015. The study was approved by the local Ethics Committee (Commission cantonale (VD) d'éthique de la recherche sur l'être humain). Due to the observational design of our study and the use of a commercially available CE marked product, the need for patient informed consent was waived.

\section{Staff Training}

Ten 'champion' nurses were selected to receive $6 \mathrm{~h}$ of specific training with Omni ${ }^{\circledR}$. Those nurses were preferentially attributed to study patients. However, due to high staff turnover, complete coverage with specifically trained nurses was not possible throughout the study.

\section{CRRT Settings}

The scheduled running time was $72 \mathrm{~h}$ as recommended by the manufacturer. Fluid removal was set by clinicians on a daily basis according to the patient's hemodynamic status and fluid balance. All therapies were performed using polyethersulfone filters $1.6 \mathrm{~m}^{2}$ (Omnifilter ${ }^{\circledR}$, B. Braun Melsungen Germany).

\section{CVVH-Heparin Mode}

In the first 6 patients, therapy was applied in CVVH pre-post dilution mode with heparin anticoagulation and MultiBic ${ }^{\circledR}$ (Fresenius ${ }^{\circledR}$, Bad Homburg, Germany) replacement solution. Typical prescribed effluent flow was slightly above $25 \mathrm{ml} / \mathrm{kg} / \mathrm{h}$ with one third replaced as pre-dilution and two thirds as post-dilution as per our usual clinical practice.

\section{CVVHD-Citrate Mode}

Therapy was applied in the CVVHD mode with regional citrate anticoagulation (CVVHD-RCA) using the modified-Morgera-protocol [5] in patients 7-10. Here, solutions consisted of $\mathrm{Na}_{3}$ Citrate $4 \%$ (Fresenius $^{\circledR}$, Bad Homburg, Germany) as a predilution anticoagulant and $\mathrm{Ci}-\mathrm{Ca}^{\circledR}$ Dialysate Plus (Fresenius ${ }^{\circledR}$, Bad Homburg, Germany) as a dialysate. As per protocol, postfilter ionized calcium was measured regularly with a target concentration between 0.25 and $0.34 \mathrm{mmol} / \mathrm{l}$. Effluent rate was set according to weight and corresponded to a dose slightly above $25 \mathrm{ml} / \mathrm{kg} / \mathrm{h}$.

\section{Catheter}

All therapies were performed using a 13Fr dual lumen central venous catheter (Gamcath Dolphin High Flow ${ }^{\circledR}$, Baxter, Deerfield, USA), with a chosen length of the catheter dependent on insertion site (jugular $20 \mathrm{~cm}$, femoral $25 \mathrm{~cm}$ ).

\section{Metabolic Parameters}

Data were collected from patients' data management system (PDMS, Metavision ${ }^{\circledR}$, iMD soft, Tel Aviv, Israel). We recorded biochemical data (in particular serum creatinine, urea, potassium and calcium) as well as blood gas analyses results (in particular $\mathrm{pH}$ and base excess). Given the noninterventional nature of our study, the frequency and need for such analyses were left to treating physicians. In general, biochemical data were obtained at least once daily, while blood gas analyses were performed between 4 and 10 times per day. The occurrence of major electrolyte disturbances was recorded separately.

\section{Therapy Data}

The following data were extracted from the Omni ${ }^{\circledR}$ device: preparation time, gross and net therapy time, filter life, achieved renal dose and number and type of alarms. These elements were cross referenced with our PDMS data for confirmation.

\section{User Satisfaction}

User satisfaction was assessed by the mean of a survey administered at the end of a series of working shifts involving CRRT application with Omni ${ }^{\circledR}$ (Cf. Appendix 1).

\section{Statistical Analysis}

All descriptive data are expressed in mean \pm SD. Derivation of descriptive statistics was made with Excel ${ }^{\circledR}$ (Microsoft, Redmond, USA) and Stata ${ }^{\circledR}$ (StataCorp, College Station, Tex., USA).

\section{Results}

\section{Patient's Characteristics}

Ten patients were enrolled and administered CRRT with Omni ${ }^{\circledR}$. Their characteristics are detailed in table 1 . Briefly, patients enrolled were predominantly (90\%) male, with a mean age of 60.2 (range 25-86). The reason for receiving CRRT was cardiogenic shock in 5 (50\%), multiple organ failure in $4(40 \%)$ and unstable hemodynamics in a patient with end-stage renal disease. All patients required mechanical ventilation and most (90\%) were in need of vasoactive drugs. Six patients were treated with a femoral catheter 4 with internal jugular and one a subclavian. One catheter was changed during the study (femoral to jugular) because of access malfunction.

\section{Running Time}

Therapy running time is presented in figure 1. Altogether, CRRT was applied with Omni ${ }^{\circledR}$ for a total duration of $617.7 \mathrm{~h}(365.6 \mathrm{~h}$ in $\mathrm{CVVH}$-heparin mode and 
Table 1. Patients characteristics

\begin{tabular}{|c|c|c|c|c|c|c|c|}
\hline Patient & Age & Gender & Main diagnosis & Reason for CRRT & $\begin{array}{l}\text { Vasoconstrictors inotropes } \\
\max \text { dose, } \mu \mathrm{g} / \mathrm{min}\end{array}$ & $\begin{array}{l}\text { Mechanical } \\
\text { ventilation }\end{array}$ & Therapy mode \\
\hline 1 & 67 & $\mathrm{~F}$ & Lyell toxic epidermal necrolysis & Multiple organ failure & NA $(0.5)$ & Yes & CVVH-heparin \\
\hline 3 & 82 & M & STEMI & Cardiogenic shock & NA (8) & Yes & CVVH-heparin \\
\hline 4 & 61 & M & Heart transplant & Cardiogenic shock & NA (20) & Yes & CVVH-heparin \\
\hline 5 & 79 & M & CABG $\times 3$ & ESRD & NA (24) & Yes & CVVH-heparin \\
\hline 8 & 45 & M & Cardiogenic shock & Cardiogenic shock & 0 & Yes & CVVHD-citrate \\
\hline 9 & 45 & M & Aortic valve replacement & Cardiogenic shock & $\begin{array}{l}\text { NA (20) } \\
\text { Milrinone (7.5) }\end{array}$ & Yes & CVVHD-citrate \\
\hline 10 & 25 & M & ARDS & Multiple organ failure & $\begin{array}{l}\text { NA (12) } \\
\text { Milrinone (10) }\end{array}$ & Yes & CVVHD-citrate \\
\hline
\end{tabular}

NA = Noradrenaline; ESRD = end-stage renal failure; $\mathrm{CABG}=$ coronary artery bypass graft; STEMI = ST elevation myocardial infarction; ARDS = acute respiratory distress syndrome.

252.1 $\mathrm{h}$ in CVVHD-RCA mode). On average, this corresponds for each patient to a mean duration of $60.9(\mathrm{SD}$ 12.5) $\mathrm{h}$ in the CVVH-heparin mode and 62.9 (SD 10.8) $\mathrm{h}$ in the CVVHD-RCA mode. Among those, therapy was actually applied (net therapy) for 54.6 (SD 13.1) $\mathrm{h}$ in the CVVH-heparin mode and 60.1 (SD 10.1) $\mathrm{h}$ in the CVVHD-RCA mode. The recirculation mode was used in 5 patients for a total duration of $12.7 \mathrm{~h}(12.2 \mathrm{~h}$ in the CVVH-heparin mode, $0.5 \mathrm{~h}$ in the CVVHD-RCA mode).

Altogether, alarms-related downtime corresponded to a total of $37.4 \mathrm{~h}(25.5 \mathrm{~h}$ in CVVH heparin mode and $11.9 \mathrm{~h}$ in CVVHD-RCA mode). This corresponds to $5.9 \%$ of total therapy time (7\% in the CVVH heparin mode and 5\% in the CVVHD-RCA mode).

\section{Circuit Lifespan}

Circuit lifespan data are presented in figure 2. Overall, 18 circuits run with CVVH-heparin (average of 3 filters per patient) with a mean circuit duration of 22.8 (SD 14.2) h (maximum $49.2 \mathrm{~h}$ ). Filter data were partially missing in 2 patients due to data corruption. Seven filters were used (1.75 filter per patient) in the CVVHD-RCA mode. In this mode, the mean circuit duration was $33.5 \mathrm{~h}$ (SD 21.3). Maximum circuit duration was $72 \mathrm{~h}$.

\section{Reasons for Therapy Interruption}

Therapy interruption was related to circuit thrombosis in 8 circuits (33\%), achieved set therapy time in $5(20.8 \%)$, low access pressures in $4(16.7 \%)$, elective end of therapy in $3(12.5 \%)$, elevated transmembrane pressures indicat-

A First Evaluation of $\mathrm{OMNI}^{\circledR}, \mathrm{A} \mathrm{New}$ Device for CRRT

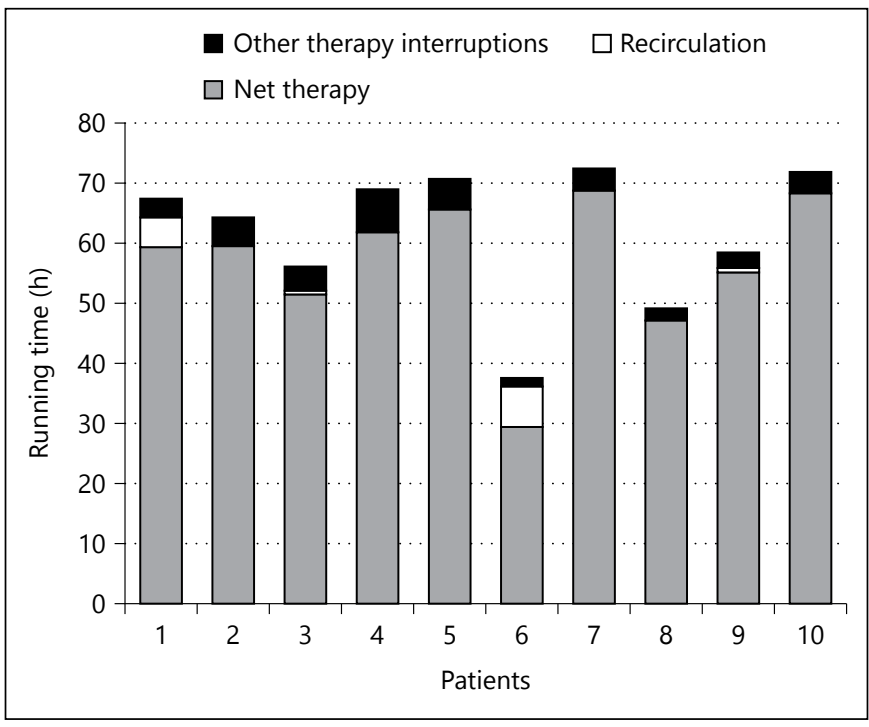

Fig. 1. Therapy running time.

ing filter saturation in $2(8.3 \%)$, access dysfunction in 1 $(4.2 \%)$, and to device-related issue in $1(4.1 \%)$. This issue related to a software limitation of maximum volume administration of the calcium solution set. Data were missing for the remaining 2 filters.

\section{Renal Dose}

As presented in figure 3 , the mean delivered renal dose in the CVVH-heparin mode was 26.3 (SD 3.8) $\mathrm{ml} / \mathrm{kg} / \mathrm{h}$ corresponding to $96 \%$ of the target 


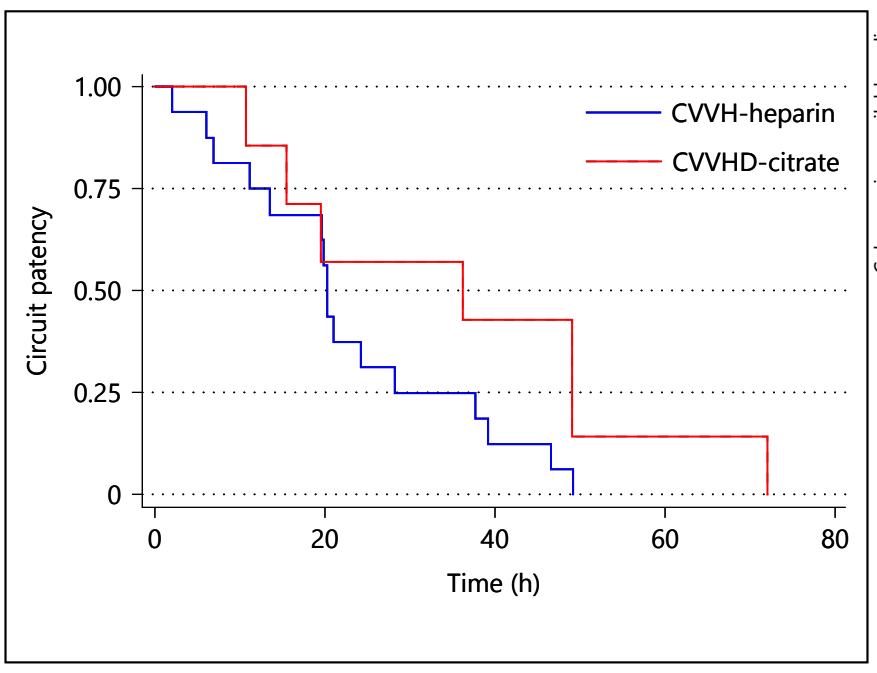

Fig. 2. Survival curves for circuit lifespan.

renal dose. In the CVVHD-RCA mode, it was 29.8 (SD 1.3 ) $\mathrm{ml} / \mathrm{kg} / \mathrm{h}$, corresponding to $98 \%$ of the target dose.

\section{Metabolic Control}

Serum levels of creatinine, potassium, arterial $\mathrm{pH}$ and base excess are presented in figure 4 . The overall, adequate metabolic control was maintained in all patients in both CVVH-heparin and CVVHD-RCA modes. In patients receiving the therapy in the CVVHD-RCA mode, there was no sign indicative of citrate intoxication; however, metabolic alkalosis ( $\mathrm{pH} 7.5$ and 7.57) was observed in 2 patients. Of note, such anomaly was already present at the start of the therapy and was corrected with dialysate rate adjustments.

\section{Fluid Balance}

Pooled fluid balances are presented in figure 5. Patient per patient data are presented in the appendix (table 1). Overall, adequate fluid control was obtained in all patients according to their hemodynamic stability and clinical situation.

\section{User Satisfaction}

Thirteen nurses including the 10 champions who received specific training returned the questionnaire. Pointby-point results are presented in figure 6 . Users appreciated the devices' functionality (rapid setup and therapy initiation), safety and design. Alarms were felt to be adequate and clear. The interface was described as easy to apprehend although slightly busy. The overall rating was 8.2/10 (SD 0.3).

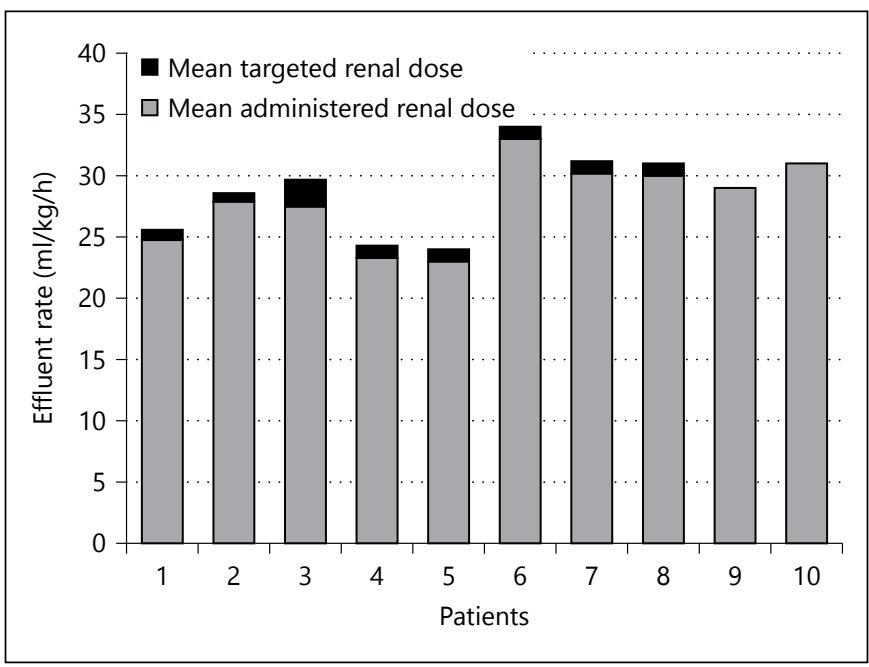

Fig. 3. Mean prescribed renal dose and mean delivered renal dose.

\section{Discussion}

\section{Key Findings}

This study reports the first utilization of Omni ${ }^{\circledR}$ to provide RRT in critically ill patients. We found that CRRT could be applied satisfactorily in both CVVH-heparin and CVVHD-RCA modes. Using this new device, we were able to maintain good metabolic control and fluid balance in all 10 patients for a total duration exceeding $600 \mathrm{~h}$. Alarms-related downtime was minimal and almost complete target renal dose delivery could be achieved. No safety concern was raised. User interface, setup, and ease of use were highly rated by nurses even despite minimal training.

\section{Comparison with Previous Studies}

We report a mean circuit lifespan of $22.8 \mathrm{~h}$ with heparin anticoagulation and $33.5 \mathrm{~h}$ with citrate anticoagulation. This is consistent with circuit lifespan reported in recent clinical trials [8-10]. In these studies, mean filter life ranged between 22.8 and $32 \mathrm{~h}$ with heparin anticoagulation and between 39.2 and $49 \mathrm{~h}$ with citrate anticoagulation. Given that this was the very first human use of this device and nursing experience was minimal, filter life is likely to be conservative and to improve with more experience.

We report a $5.9 \%$ downtime due to alarm interruptions. To the best of our knowledge, our study is the first to report such an outcome. However, the $96.6 \%$ renal dose achievement suggests adequate therapy delivery consistent with adequate metabolic control. This deliv-
Schläpfer/Durovray/Plouhinec/Chiappa/ Bellomo/Schneider 


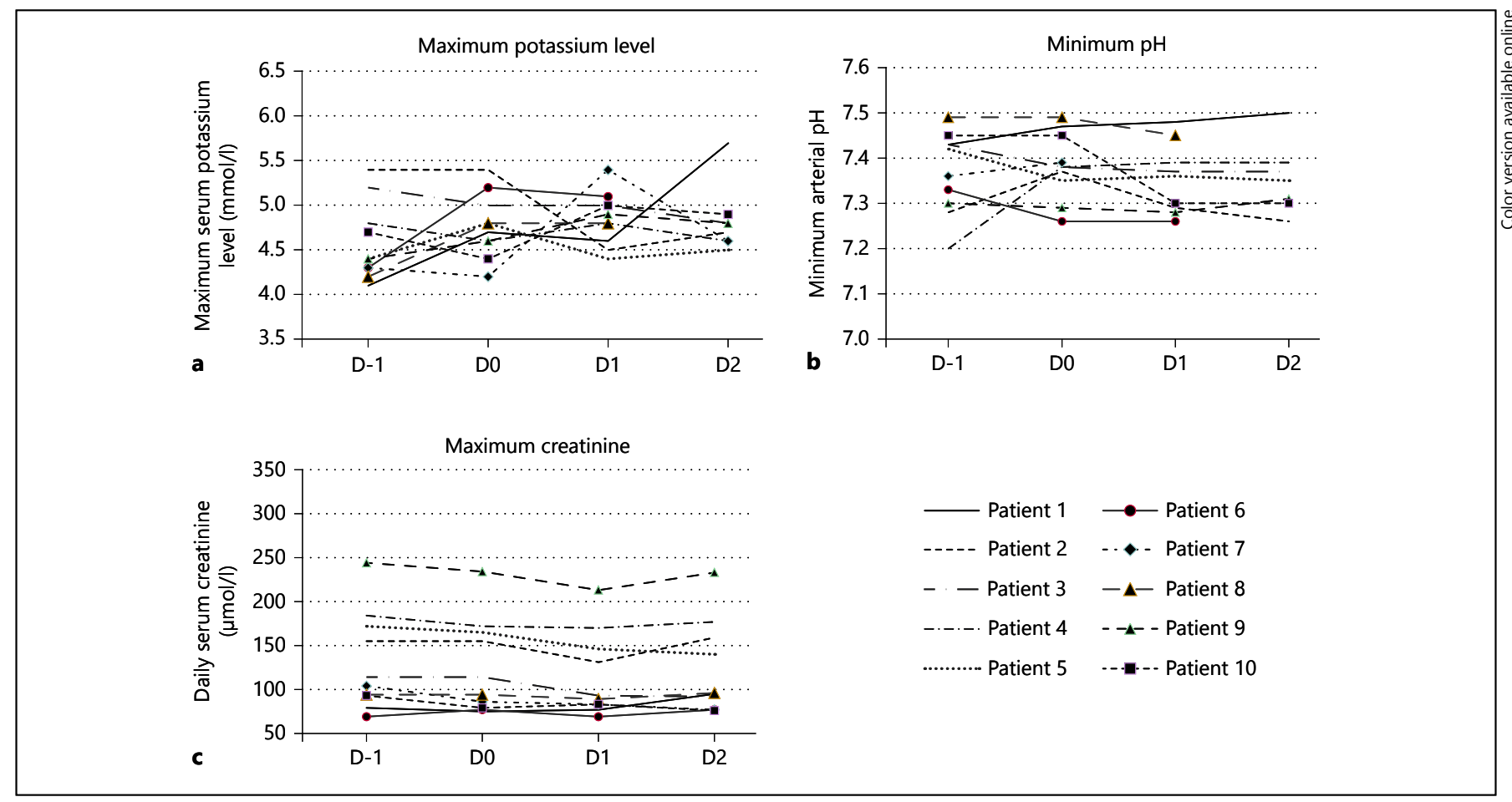

Fig. 4. Metabolic control. a Lowest arterial pH. b Maximum serum potassium level. c Maximum serum creatinine level. D-1 = Day before the initiation of therapy with Omni ${ }^{\circledR} ; \mathrm{D} 0=$ day of therapy initiation; D1 = day following therapy initiation; D2 = second day following therapy initiation.

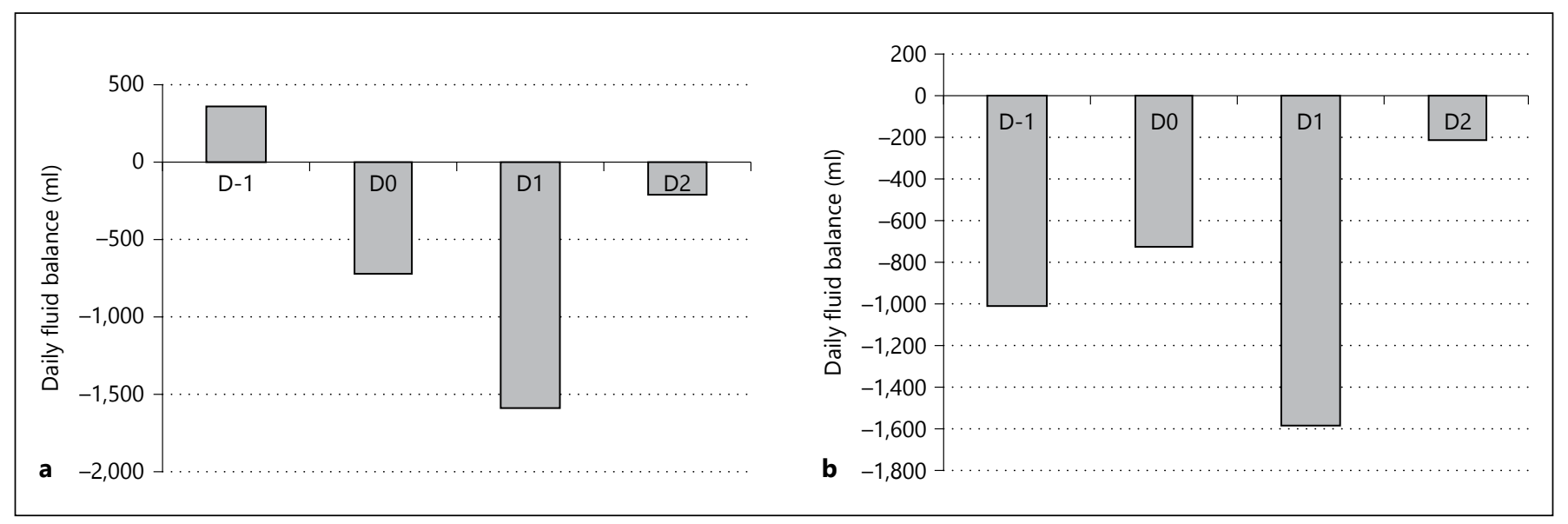

Fig. 5. Pooled daily fluid balances. a Patients $1-6$ (received CRRT in CVVH heparin mode). b Patients 7-10 (received CRRT in CVVHD-Citrate mode). Patient per patient data is available in Ap-

ered/prescribed ratio is higher than those reported in the 2 major randomized controlled trials comparing RRT dose $[15,16]$. Indeed, in the ATN trial [15], 89\% of the prescribed dose was delivered in the 'high-intensity' group and $95 \%$ in the 'low-intensity group'. In the RENAL pendix 2. D-1 = Day before the initiation of therapy with Omni ${ }^{\circledR}$; $\mathrm{D} 0$ = day of therapy initiation; D1 = day following therapy initiation; D2 = second day following therapy initiation.

trial [16], it was $84 \%$ in the 'high-intensity' group and $88 \%$ in the 'low-intensity' group. This promising result is possibly related to the device and its ability to compensate for alarms associated downtime automatically increasing effluent dose. 


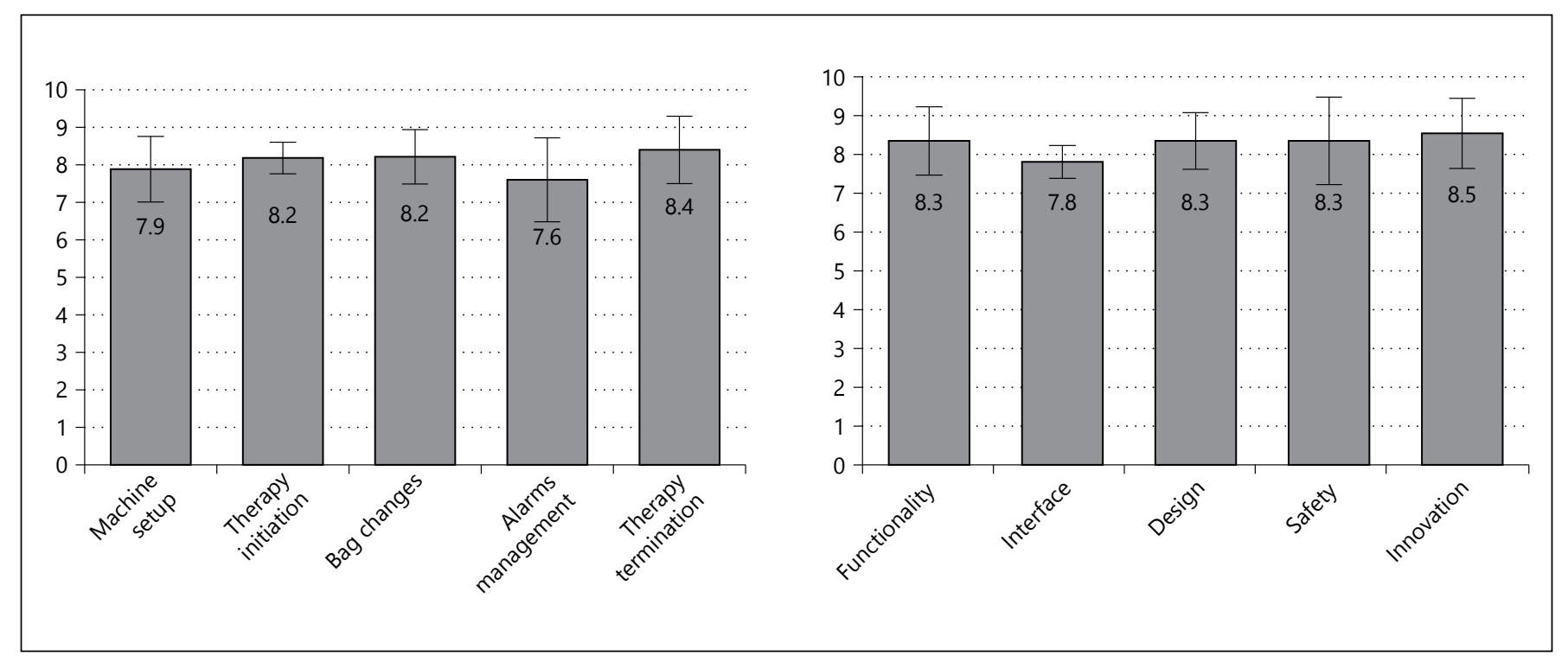

Fig. 6. Results of the user satisfaction survey (13 respondents).

\section{Implication for Clinicians and Policy Makers}

This study reports safe and efficient use of Omni ${ }^{\circledR}$ to provide RRT in critically ill patients. It suggests that it can be used even with minimal training by nurses with RRT experience. Their evaluation of the device was highly positive. Further studies are required to evaluate the impact of such devices on outcomes in such patients.

\section{Strengths and Limitations}

This study reports the first series of patients ever treated with this new (fourth)-generation CRRT device. It demonstrates the safety and feasibility of applying such therapy in critically ill patients in both CVVH-heparin and CVVHD-RCA modes with this device. Our study also illustrates its capacity to run with minimal interruptions and compensate for them, minimizing downtime and optimizing renal dose delivery.

Our study was conducted in a large tertiary level center with a high level of experience with RRT and high nurse to patient ratio (1:1.2). Indeed, more than $1,200 \mathrm{RRT}$ sessions in more than 150 patients are provided on a yearly basis in our unit. Therefore, our conclusions need to be confirmed or refuted by data originated from smaller centers with less practice with RRT and lower nurse to patient ratio.

For this study, the therapy was applied with dialysate and replacement solutions from another manufacturer (Fresenius ${ }^{\circledR}$, Bad Homburg, Germany) and correspond- ing protocols. Our findings therefore only apply to the device itself. Further testing using manufacturers' solutions need to be undertaken.

\section{Conclusions}

RRT could be provided using Omni ${ }^{\circledR}$ in a safe and efficient way in both CVVH-heparin and CVVHD-RCA modes in 10 critically ill patients. Alarms-related downtime was minimal and renal dose delivery high. Users provided positive feedback for therapy setup, management and design.

\section{Acknowledgments}

The investigators wish to address their special thanks to our nurse champions: Karima Alouazem, Laure Bonjour, Souad Derrar, Thibaud Favy, Lise Grepillat, Luca Imperatori, Pierre-Henri Ngoboka, Sabrina Patthey, David Rioual, Madeleine Schnorf, Michèle Wieser.

\section{Disclosure Statement}

The study was an observational study conducted in parallel to a 'Field Acceptance Test,' which was sponsored by B. Braun Melsungen AG. However, B. Braun had no influence on the study design, results interpretation, manuscript preparation and decision of submission. Dr. Antoine Schneider and Dr. Rinaldo Bellomo have received consulting and speaking support from B. Braun SA. 


\section{Appendix 1}

\section{Préparation machine}

$\begin{array}{llllllllll}1 & 2 & 3 & 4 & 5 & 6 & 7 & 8 & 9 & 10\end{array}$

Connexion patient/débuter traitement

$\begin{array}{llllllllll}1 & 2 & 3 & 4 & 5 & 6 & 7 & 8 & 9 & 10\end{array}$

Changements sets/poches

$\begin{array}{llllllllll}1 & 2 & 3 & 4 & 5 & 6 & 7 & 8 & 9 & 10\end{array}$

$\begin{array}{llllllllll}\text { Changements modes traitement/dilution } \\ 1 & 2 & 3 & 4 & 5 & 6 & 7 & 8 & 9 & 10\end{array}$

Gestion des alarmes

$\begin{array}{llllllllll}1 & 2 & 3 & 4 & 5 & 6 & 7 & 8 & 9 & 10\end{array}$

Arrêt du traitment (arrêt machine et retrait du set)

$\begin{array}{llllllllll}1 & 2 & 3 & 4 & 5 & 6 & 7 & 8 & 9 & 10\end{array}$

Fonctionnalité

$\begin{array}{llllllllll}1 & 2 & 3 & 4 & 5 & 6 & 7 & 8 & 9 & 10\end{array}$

$\begin{array}{llllllllll}\text { Interface } & & & & & & 8 & & & 10 \\ 1 & 2 & 3 & 4 & 5 & 6 & 7 & 8 & 9 & 10\end{array}$

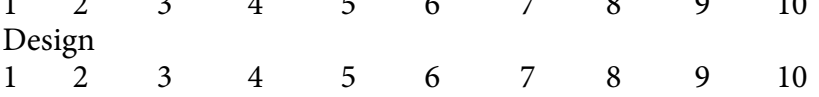

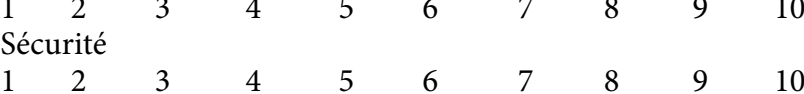

$\begin{array}{lllllllll}\text { Innovation } & & & & & & & \\ 1 & 2 & 3 & 4 & 5 & 6 & 7 & 8 & 9\end{array}$

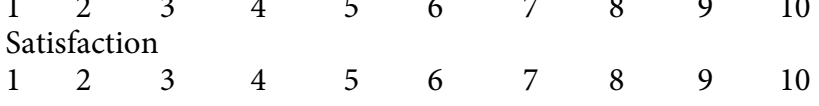

\section{Appendix 2}

Daily fluid balances (milliliters)

\begin{tabular}{lllll}
\hline Patient & D-1 & D0 & D1 & D2 \\
\hline 1 & 1,672 & 1,411 & 397 & $-1,440$ \\
2 & $-1,480$ & $-2,135$ & $-2,860$ & $-1,875$ \\
3 & 41 & 217 & -377 & $-2,016$ \\
4 & 3,879 & 2,611 & $-1,407$ & $-2,639$ \\
5 & $-1,576$ & $-1,023$ & -335 & 302 \\
6 & -392 & -384 & -474 & $-2,167$ \\
7 & 392 & $-1,096$ & -947 & -212 \\
8 & $-1,994$ & -719 & $-2,507$ & \\
9 & $-1,093$ & -736 & $-2,229$ & $-1,719$ \\
10 & $-1,328$ & -16 & 1,482 & 695 \\
\hline
\end{tabular}

D-1 = Day before the initiation of therapy with Omni ${ }^{\circledR} ; \mathrm{D} 0=$ day of therapy initiation; D1 = day following therapy initiation; D2 = second day following therapy initiation.

\section{References}

1 Kramer P, Wigger W, Rieger J, Matthaei D, Scheler F: [Arteriovenous haemofiltration: a new and simple method for treatment of overhydrated patients resistant to diuretics]. Klin Wochenschr 1977;55:1121-1122.

2 Mehta RL, McDonald BR, Aguilar MM, Ward DM: Regional citrate anticoagulation for continuous arteriovenous hemodialysis in critically ill patients. Kidney Int 1990;38:976-981.

3 Oudemans-van Straaten HM, Bosman RJ, Koopmans M, van der Voort PH, Wester JP, van der Spoel JI, Dijksman LM, Zandstra DF: Citrate anticoagulation for continuous venovenous hemofiltration. Crit Care Med 2009; 37:545-552.

4 Bai M, Zhou M, He L, Ma F, Li Y, Yu Y, Wang P, Li L, Jing R, Zhao L, Sun S: Citrate versus heparin anticoagulation for continuous renal replacement therapy: an updated meta-analysis of RCTs. Intensive Care Med 2015;41: 2098-2110.

5 Morgera S, Schneider M, Slowinski T, VargasHein O, Zuckermann-Becker H, Peters H, Kindgen-Milles D, Neumayer HH: A safe citrate anticoagulation protocol with variable treatment efficacy and excellent control of the acid-base status. Crit Care Med 2009;37: 2018-2024.

6 Tolwani AJ, Prendergast MB, Speer RR, Stofan BS, Wille KM: A practical citrate anticoagulation continuous venovenous hemodiafiltration protocol for metabolic control and high solute clearance. Clin J Am Soc Nephrol 2006; 1:79-87.

7 Morabito S, Pistolesi V, Tritapepe L, Fiaccadori E: Regional citrate anticoagulation for RRTs in critically ill patients with AKI. Clin J Am Soc Nephrol 2014;9:2173-2188.

8 Stucker F, Ponte B, Tataw J, Martin PY, Wozniak H, Pugin J, Saudan P: Efficacy and safety of citrate-based anticoagulation compared to heparin in patients with acute kidney injury requiring continuous renal replacement therapy: a randomized controlled trial. Crit Care 2015;19:91.

9 Gattas DJ, Rajbhandari D, Bradford C, Buhr H, Lo S, Bellomo R: A randomized controlled trial of regional citrate versus regional heparin anticoagulation for continuous renal replacement therapy in critically ill adults. Crit Care Med 2015;43:1622-1629.

10 Schilder L, Nurmohamed SA, Bosch FH, Purmer IM, den Boer SS, Kleppe CG, Vervloet MG, Beishuizen A, Girbes AR, Ter Wee PM, Groeneveld AB; CASH Study Group: Citrate anticoagulation versus systemic heparinisation in continuous venovenous hemofiltration in critically ill patients with acute kidney injury: a multi-center randomized clinical trial. Crit Care 2014;18:472.

11 Ronco C, Ricci Z, De Backer D, Kellum JA, Taccone FS, Joannidis M, Pickkers P, Cantaluppi V, Turani F, Saudan P, Bellomo R, Joannes-Boyau O, Antonelli M, Payen D,
Prowle JR, Vincent JL: Renal replacement therapy in acute kidney injury: controversy and consensus. Crit Care 2015;19:146.

12 Ronco C, Ricci Z, Bellomo R, Baldwin I, Kellum J: Management of fluid balance in CRRT: a technical approach. Int J Artif Organs 2005; 28:765-776.

13 Houllè-Veyssière $M$, Courtin A, Zeroual N, Gaudard P, Colson PH: Continuous venovenous renal replacement therapy in critically ill patients: a work load analysis. Intensive Crit Care Nurs 2016;36:35-41.

14 Fealy N, Aitken L, Toit Ed, Baldwin I: Continuous renal replacement therapy: current practice in Australian and New Zealand intensive care units. Crit Care Resusc 2015;17: 83-91.

15 VA/NIH Acute Renal Failure Trial Network, Palevsky PM, Zhang JH, O'Connor TZ, Chertow GM, Crowley ST, Choudhury D, Finkel K, Kellum JA, Paganini E, Schein RM, Smith MW, Swanson KM, Thompson BT, Vijayan A, Watnick S, Star RA, Peduzzi P: Intensity of renal support in critically ill patients with acute kidney injury. N Engl J Med 2008;359: 7-20.

16 Bellomo R, Cass A, Cole L, Finfer S, Gallagher M, Lo S, McArthur C, McGuinness S, Myburgh J, Norton R, Scheinkestel C, Su S: Intensity of continuous renal-replacement therapy in critically ill patients. N Engl J Med 2009;361:1627-1638. 